\title{
Identification of different clonal complexes and diverse amino acid substitutions in penicillin- binding protein 2 (PBP2) associated with borderline oxacillin resistance in Canadian Staphylococcus aureus isolates
}

\begin{abstract}
Correspondence
Martin J. McGavin

martin.mcgavin@sri.utoronto.ca
\end{abstract}

Received 26 April 2006

Accepted 8 August 2006

\author{
Jeya Nadarajah, ${ }^{1}$ Mark J. S. Lee, ${ }^{1}$ Lisa Louie, ${ }^{1}$ Latha Jacob, ${ }^{1}$ \\ Andrew E. Simor, ${ }^{1}$ Marie Louie ${ }^{2}$ and Martin J. McGavin ${ }^{1}$ \\ ${ }^{1}$ University of Toronto Department of Laboratory Medicine and Pathobiology, and Sunnybrook \\ and Women's College Health Sciences Centre, Department of Microbiology, Toronto, ON, \\ Canada \\ ${ }^{2}$ University of Calgary, Calgary, $A B$, Canada
}

\begin{abstract}
Borderline oxacillin-resistant Staphylococcus aureus (BORSA) exhibit oxacillin MIC values of 1-8 $\mu \mathrm{g} \mathrm{ml}^{-1}$, but lack $m e c A$, which encodes the low-affinity penicillin-binding protein (PBP)2a. The relationship of the BORSA phenotype with specific genetic backgrounds was assessed, as well as amino acid sequence variation in the normal PBP2. Among 38 BORSA, 26 had a common PFGE profile of genomic DNA, and were multilocus sequence type (ST)25. The other isolates were genetically diverse. Complete $p b p 2$ sequences were determined for three BORSA, corresponding to ST25, ST1 and ST47, which were selected on the basis of lacking blaZ-encoded $\beta$-lactamase. The essential transpeptidase-domain-encoding segment of $p b p 2$ was also sequenced from seven additional ST25 isolates. Amino acid substitutions occurred in the transpeptidase domain of all BORSA, irrespective of clonal type. A Gln ${ }_{629} \rightarrow$ Pro substitution was common to all ST25 BORSA, but most could be distinguished from one another by additional unique substitutions in the transpeptidase domain. The ST1 and ST47 isolates also possessed unique substitutions in the transpeptidase domain. Plasmid-mediated expression of pbp2 from an ST25 or ST1 isolate in S. aureus RN6390 increased its oxacillin MIC from 0.25 to $4 \mu \mathrm{g} \mathrm{ml}^{-1}$, while pbp2 from a susceptible strain, ATCC 25923, had no effect. Therefore, different amino acid substitutions in PBP2 of diverse BORSA lineages contribute to borderline resistance. The predominant ST25 lineage was not related to any of the five clonal complexes that contain meticillin-resistant S. aureus (MRSA), suggesting that ST25 cannot readily acquire mecA-mediated resistance.
\end{abstract}

\section{INTRODUCTION}

Staphylococcus aureus is a leading cause of nosocomial infections, and is distinguished by its ability to cause infection in virtually every tissue and organ system of the body (Archer, 1998). Therefore, rapid eradication of $S$. aureus is of paramount importance in the treatment and

Abbreviations: BORSA, borderline oxacillin-resistant S. aureus; CC, clonal complex; MLST, multilocus sequence typing; MRSA, meticillinresistant S. aureus; MSSA, meticillin-susceptible $S$. aureus; PBP, penicillin-binding protein; ST, sequence type.

The GenBank/EMBL/DDBJ accession numbers of pbp2 sequences determined from strains MA15 and $\mathrm{MSH} 12$ in this study are AF540019 and AF540020, respectively. Accession numbers AF540021-AF540028 were assigned for the respective partial nucleotide sequences of pbp2 from additional BORSA isolates MA4, MA6, MA8, MA9, MA13, MA14, MSH7 and OGH2. control of nosocomial infections. However, the introduction of penicillin into clinical practice was quickly followed by the appearance of $\beta$-lactamase-mediated resistance. The introduction of $\beta$-lactamase-resistant semi-synthetic forms of penicillin was also quickly followed by the acquisition of an alternative penicillin-binding protein (PBP), PBP2a, encoded by mecA on the staphylococcal cassette chromosome SCCmec (Hiramatsu et al., 2001; Ito et al., 2001). Meticillin-resistant $S$. aureus (MRSA) are resistant to all members of the $\beta$-lactam family, due to the low affinity of PBP2a for $\beta$-lactams (Hartman \& Tomasz, 1984). As endemic hospital-associated MRSA are typically resistant to multiple antimicrobial agents, an increased emphasis has been placed on their rapid identification, both for determining an appropriate antimicrobial regimen, and to enable appropriate infection control measures (Louie et al., 2000; van Griethuysen et al., 2001; Yamazumi et al., 2001). A 
by-product of the quest for more sensitive diagnostic techniques has been the identification of strains with an intermediate level of resistance, known as borderline oxacillin-resistant S. aureus (BORSA) (Varaldo, 1993; Varaldo et al., 1993).

Although BORSA infections can be treated with $\beta$-lactams (Varaldo, 1993), outbreaks continue to occur (Balslev et al., 2005); BORSA have been associated with both communityacquired and nosocomial infections in multiple institutions, and have been isolated from various infection sites, including skin and surgical wounds (Kernodle et al., 1998; Massanari et al., 1988; Suggs et al., 1999). Although BORSA do not exhibit a single trait that differentiates them from fully susceptible or resistant strains, many share a common 94/96 phage type, a high degree of genetic relatedness, and a $17 \cdot 2 \mathrm{~kb}$ plasmid that confers hyper-production of $\beta$ lactamase (Barg et al., 1991; Massidda et al., 1996; McMurray et al., 1990). This last feature has been proposed as a factor that contributes to the BORSA phenotype (Barg et al., 1991; McDougal \& Thornsberry, 1986), as well as a novel meticillinase (Keseru et al., 2005; Massidda et al., 1992). Others have noted that spontaneous amino acid substitutions in PBP2 of $S$. aureus can be induced by selection for growth in the presence of ceftizoxime (Leski \& Tomasz, 2005), and different substitutions in PBP2 have been noted in one study conducted with a single clinical BORSA strain, CDC-6 (Hackbarth et al., 1995).

Although these archetypal BORSA share a high degree of genetic relatedness, several issues are unresolved, including their association with the overall population structure of $S$. aureus, which is predominantly clonal (Feil et al., 2003, 2004; Feil \& Enright, 2004), the extent to which amino acid substitutions in PBP2 from the BORSA strain CDC-6 are shared by other related BORSA, and the presence of amino acid substitutions in PBP2 from BORSA strains that do not conform to the prototypic 94/96 phage type strains represented by CDC- 6 . In this respect, diverse amino acid substitutions within the equivalent of PBP2 in Streptococcus pneumoniae also promote reduced susceptibility to $\beta$ lactams (Asahi et al., 1999; Mouz et al., 1999). However, the genetic competence of Strep. pneumoniae and its capacity for interspecies recombination have contributed to a mosaic structure of PBP in penicillin-resistant strains (Dessen et al., 2001; Laible et al., 1991), whereas S. aureus is not noted for genetic competence (Tortosa \& Dubnau, 1999), and is more likely to alter gene function by point mutation than genetic recombination (Feil et al., 2003, 2004; Feil \& Enright, 2004). Herein, we report on the clonal associations of genetically diverse BORSA, an analysis of amino acid substitutions in their PBP2s, and the contribution of the latter to the BORSA phenotype.

\section{METHODS}

Bacterial strains, plasmids and growth media. Regional healthcare centres from across Canada were requested to submit $S$. aureus strains that exhibited an oxacillin MIC $\geqslant 1$ and $\leqslant 8 \mu \mathrm{g} \mathrm{ml}^{-1}$, but were mecA negative. All strains that satisfied these criteria were confirmed as $S$. aureus which lacked $m e c A$, using a multiplex PCR assay that detected both the nuclease gene (specific for $S$. aureus) and mecA, with detection of bacterial $16 \mathrm{~S}$ rRNA as an internal control, as described previously (Louie et al., 2002). Control organisms used with each batch of samples tested included S. aureus ATCC 43300 (MRSA) and meticillin-susceptible S. aureus (MSSA) ATCC 29213. By these criteria, 38 BORSA were collected over a period of 8 years (1990-1998). The isolates were from different geographic locations in Quebec, Ontario and Manitoba, and deemed to be epidemiologically unrelated, as evident either from the identification of distinct genetic backgrounds or from the existence of strains of a similar genetic background that originated from different locations or non-overlapping time spans.

Confirmed BORSA were subjected to antibiotic-susceptibility testing, using cation-adjusted Mueller-Hinton broth supplemented with $2 \%$ $\mathrm{NaCl}$, unless otherwise indicated, according to standard guidelines (National Committee for Clinical Laboratory Standards, 2003). Phage typing and PFGE of SmaI-digested genomic DNA were conducted as described previously (Simor et al., 2001, 2002). Additional strains and plasmids used in this study are described in Table 1. S. aureus was grown at $37^{\circ} \mathrm{C}$ in brain heart infusion (BHI) broth (Difco). Escherichia coli was grown at $37^{\circ} \mathrm{C}$ in Luria-Bertani medium (Difco). Media were supplemented with chloramphenicol $\left(10 \mu \mathrm{g} \mathrm{ml}^{-1}\right)$ or ampicillin $\left(50 \mu \mathrm{g} \mathrm{ml}^{-1}\right)$, where appropriate.

Plasmid isolation and Southern hybridization. Plasmid isolation from either E. coli or S. aureus was performed using reagents provided with the GenElute plasmid kit (Sigma), using a lysostaphin treatment step for $S$. aureus, as necessary. Southern hybridization of HindIII-digested genomic DNA was performed as described previously (Rice et al., 2001), using the Amersham ECL Direct chemiluminescence labelling system. A 316 bp probe representing the $3^{\prime}$ end of the S. aureus blaZ-coding sequence was generated by PCR with the forward and reverse primers $5^{\prime}$-TTCAACACCTGCTGCTTTC-3' and $5^{\prime}$-CACTCTTGGCGGTTTCAC-3', using genomic DNA of $S$. aureus ATCC 29213 as template.

Cloning and sequencing of $\mathbf{p b p 2}$. The $p b p 2$ gene is preceded by prfA (Pinho et al., 1998), encoding a putative DNA recombination and repair function, and the two genes can be transcribed independently or as a polycistronic RNA originating from the prfA promoter. To ensure optimal expression, PCR of genomic DNA was employed to amplify a $3 \cdot 2 \mathrm{~kb}$ fragment, containing $p$ frApbp2, using forward and reverse primers $5^{\prime}$-cgggatccCACATACTTGTACTTGCCTC-3' and 5' -cccgagctcTTTATGTTGAGTGGA-3', respectively. A $1.28 \mathrm{~kb}$ fragment spanning the transpeptidase domain (amino acids 278-701) of pbp2 was amplified with primers $5^{\prime}$ cgggatccGCGAACTTAGTAAATCGTACTCCTG-3' and $5^{\prime}$-gggctgcagCTGCTGTTGCTGATGTGTC-3'. Underlined lower-case nucleotides represent added BamHI, PstI or SacI restriction enzyme sites required for cloning. PCR was performed with AmpliTaq Gold (Roche), and the products were cloned into E. coli $\mathrm{INV}_{\mathrm{N}} \mathrm{F}^{\prime}$, using the pCR2.1 vector and protocols provided with the Original TA Cloning system (Invitrogen). Plasmid DNA was extracted from selected clones, and sequenced by the University of Toronto Hospital for Sick Children DNA sequencing facility. The $3 \cdot 2 \mathrm{~kb}$ prapbp2 fragments were excised from pCR2.1 with BamHI and SacI, ligated with plasmid pRN5548 (Novick et al., 1993), and electroporated into S. aureus RN4220 and RN6390 as detailed in Table 1.

Nucleotide sequence analyses and multilocus sequence typing (MLST). Sequences obtained from this study were compared to $p b p 2$ from $S$. aureus strains for which genome sequences are available, and other strains for which $p b p 2$ sequences have been 
Table 1. Plasmids and strains used in this study

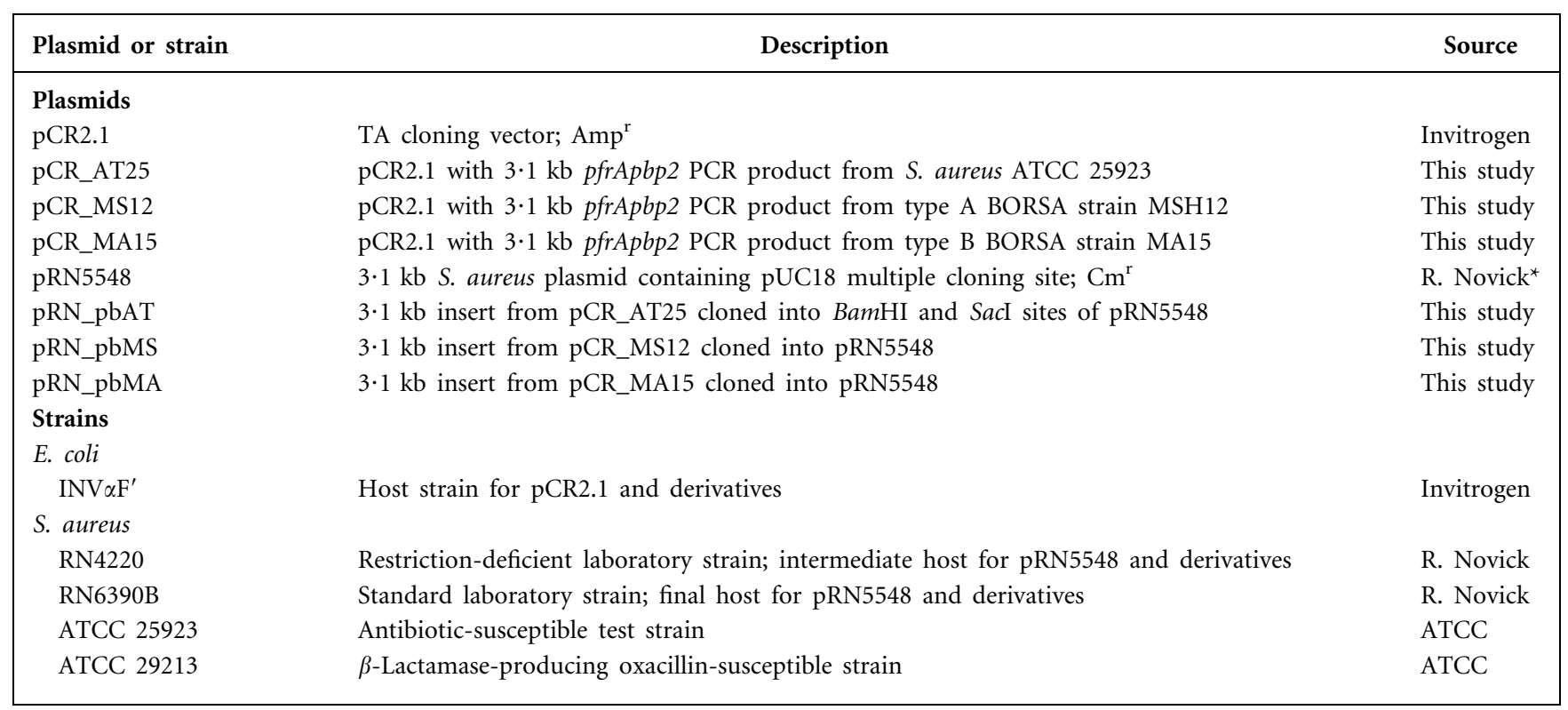

*Skirball Institute of Biomolecular Medicine, New York University School of Medicine.

published or deposited in GenBank, as detailed in Table 2. The accession numbers of $p b p 2$ sequences determined from strains MA15 and MSH12 in this study are AF540019 and AF540020, respectively. Accession numbers AF540021-AF540028 were assigned for the respective partial nucleotide sequences of $p b p 2$ from additional BORSA isolates MA4, MA6, MA8, MA9, MA13, MA14, MSH7 and OGH2.
MLST was conducted as described for S. aureus (Enright et al., 2000) using seven gene loci: $\operatorname{arc\mathrm {C}}, \operatorname{aro\mathrm {E}}, g l p \mathrm{~F}, g m k$, $p t a$, tpi and $y q i$. Each PCR amplicon was sequenced using the forward and reverse primers that were employed for amplification. Automated data analyses and assignment of STs were conducted using the programs provided by the http://saureus.mlst.net/ site, hosted at Imperial College, London, and funded by the Wellcome Trust.

Table 2. S. aureus strains for which PBP2 sequences are known

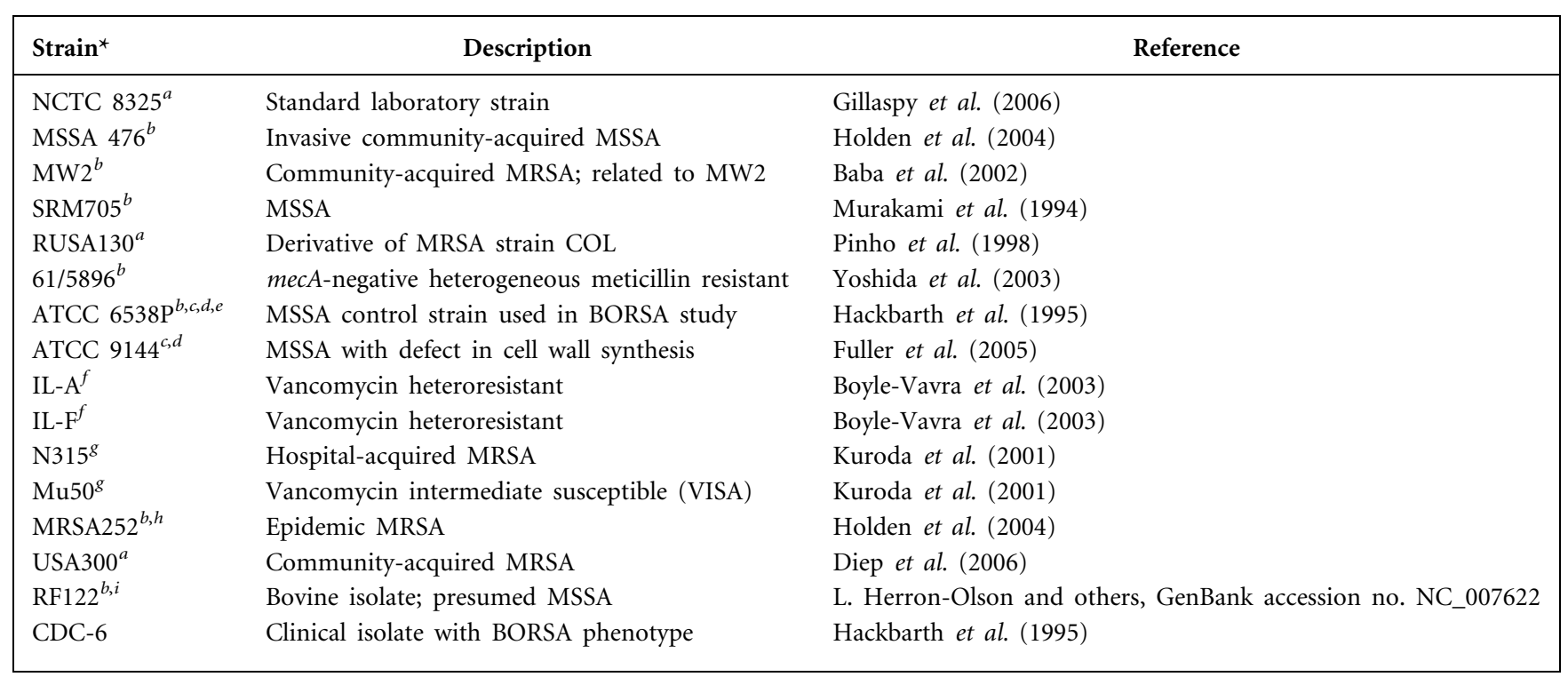

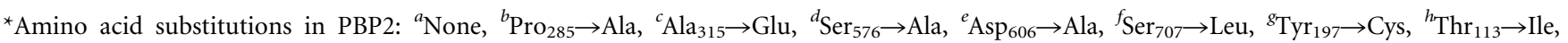
${ }^{i} \mathrm{Thr}_{439} \rightarrow$ Val. 


\section{RESULTS AND DISCUSSION}

\section{Genotypic and phenotypic characterization of BORSA}

Genetic diversity among 38 BORSA was assessed by phage typing and PFGE of SmaI-digested genomic DNA using established protocols (Simor et al., 2001, 2002). The plasmid profile of each BORSA isolate was also assessed by agarose gel electrophoresis. The details of representative isolates are presented in Table 3 . The majority of BORSA $(n=26)$ possessed an identical 'type A' PFGE profile of SmaIdigested genomic DNA, and the $94 / 96$ phage type (group 5) that was previously noted as a common feature of BORSA (Kernodle et al., 1998). Most type A BORSA $(n=20)$ possessed blaZ on a $17 \cdot 2 \mathrm{~kb}$ plasmid, as previously noted for BORSA of the 94/96 phage type (Massidda et al., 1996; McMurray et al., 1990). However, six BORSA did not possess a plasmid. Southern hybridization of HindIIIdigested genomic DNA with a probe specific for blaZ revealed that five of these carried a genomic copy of blaZ (data not shown), while a single strain MSH12 did not have blaZ (Table 3). MLST revealed that MSH12 and two other type A BORSA (MA8 and MA14) were ST25 (Table 3). The 12 BORSA that were not PFGE type A had diverse phage types and eight different PFGE patterns (B-I); they included strains MA15 and MA6, corresponding to ST1 and ST47, respectively, which also did not harbour blaZ (Table 3). These two strains, together with MSH12, exhibited MIC values of $1-2 \mu \mathrm{g} \mathrm{ml}^{-1}$ for penicillin, and $4-8 \mu \mathrm{g} \mathrm{ml}^{-1}$ for oxacillin (Table 3). Other isolates that possessed blaZ maintained MIC values of $2-8 \mu \mathrm{g} \mathrm{ml}^{-1}$ for oxacillin, whereas the MIC for penicillin was greater than $64 \mu \mathrm{g} \mathrm{ml}^{-1}$ (Table 3).

Based on these data, we conclude that hyperproduction of $\beta$ lactamase is not necessary to promote a BORSA phenotype. Although we cannot exclude the possibility of a novel meticillinase that has been described elsewhere (Keseru et al.,
2005; Massidda et al., 1992), such an enzyme would have to exhibit little or no activity towards penicillin to account for the low penicillin MIC values that were noted in the few BORSA that lack blaZ.

\section{Analysis of amino acid substitutions in PBP2}

PBP2 is a 727 amino acid protein, with an N-terminal transglycosylase domain spanning amino acids 76-244, and a C-terminal transpeptidase domain spanning amino acids 360-653 (Fig. 1) that is essential for peptidoglycan crosslinking (Pinho et al., 2001a,b), and is inhibited by the $\beta$ lactam family of antibiotics. PBPs also have conserved penicillin-binding motifs (Frere \& Joris, 1985; Ghuysen, 1991, 1994), which in PBP2 of S. aureus consist of ${ }_{398}$ SSLK, ${ }_{454} \mathrm{SFN}$ and ${ }_{583} \mathrm{KTG}$ (Fig. 1), with $\mathrm{Ser}_{398}$ being the primary active site serine. We anticipated that if variation in PBP2 was responsible for the BORSA phenotype, we would detect amino acid substitutions in the transpeptidase domain of BORSA strains, but not in known PBP2 sequences from MSSA or MRSA.

We first used the BLAST program (www.ncbi.nlm.nih.gov/ blast) to assess variation among known PBP2 sequences obtained from S. aureus genomes or GenBank depositions, as listed in Table 2. Three strains (COL, USA300 and NCTC 8325-4) had identical sequences, relative to which several others had a limited number of amino acid substitutions, in the N-terminal transglycosylase domain $\left(\mathrm{Thr}_{113} \rightarrow\right.$ Ile; $\mathrm{Tyr}_{197} \rightarrow$ Cys), in a spacer segment that separates the transglycosylase and transpeptidase domain $\left(\mathrm{Pro}_{285} \rightarrow \mathrm{Ala}\right.$; $\mathrm{Ala}_{315} \rightarrow \mathrm{Glu}$ ), or close to the C-terminus ( $\mathrm{Ser}_{707} \rightarrow \mathrm{Leu}$ ) (Fig. 1, Table 2). Strains ATCC 9144 and ATCC 6538P possessed one or two substitutions in the transpeptidase domain, but are both MSSA (Fuller et al., 2005; Hackbarth et al., 1995). The bovine strain RF122, which also harboured a unique substitution in the transpeptidase domain, is described as being penicillin sensitive (Fitzgerald et al., 2000), and is also assumed to be MSSA. Therefore, among

Table 3. Genotypic and phenotypic traits of BORSA isolates characterized in this study

\begin{tabular}{|c|c|c|c|c|c|c|c|c|}
\hline \multirow[t]{2}{*}{ Strain } & \multirow[t]{2}{*}{ Origin $^{\star}$} & \multicolumn{2}{|c|}{ MIC $\left(\mu \mathrm{g} \mathrm{ml}^{-1}\right)$ for: } & \multirow[t]{2}{*}{ blaZ } & \multirow[t]{2}{*}{$17 \cdot 2 \mathrm{~kb}$ plasmid } & \multirow[t]{2}{*}{ Phage type } & \multirow[t]{2}{*}{ PFGE profile } & \multirow[t]{2}{*}{ MLST type } \\
\hline & & Oxacillin & Penicillin & & & & & \\
\hline MSH12 & $\mathrm{T}$ & 8 & 2 & - & - & $94 / 96$ & A & ST25 \\
\hline MA4 & M & 4 & 128 & + & + & $94 / 96$ & A & \\
\hline MA6 & M & 4 & 1 & - & - & 95 & $\mathrm{~F}$ & ST47 \\
\hline MA9 & M & 4 & 256 & + & + & $94 / 96$ & A & \\
\hline MA13 & M & 8 & 256 & + & + & $29 ; 94 / 96$ & A & \\
\hline MA14 & M & 8 & 64 & + & $(16 \cdot 7 \mathrm{~kb})$ & $94 / 96$ & A & ST25 \\
\hline MSH7 & $\mathrm{T}$ & 2 & 128 & + & - & $94 / 96$ & A & \\
\hline OGH2 & $\mathrm{O}$ & 4 & 128 & + & + & $94 / 96$ & A & \\
\hline
\end{tabular}

${ }^{\star} \mathrm{M}$, Montreal; T, Toronto; O, Ottawa. 


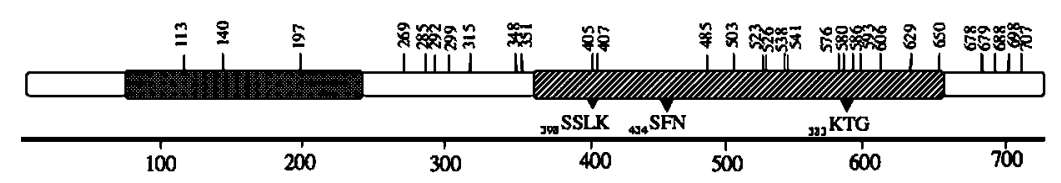

Fig. 1. Scale diagram of PBP2, showing the location of the $\mathrm{N}$-terminal transglycosylase domain (stippled) and C-terminal transpeptidase domain (diagonal hatching). The location and sequence of penicillin-binding motifs are indicated by inverted black triangles below the transpeptidase domain. Numbers above PBP2 indicate the location of amino acid substitutions in all known PBP2s, including BORSA strains characterized in this study, relative to PBP2 of $S$. aureus strains ATCC 25923, NCTC 8325 and COL, which harbour identical PBP2 sequences. Two substitutions, $\mathrm{Ala}_{450} \rightarrow$ Asp and $\mathrm{Ala}_{462} \rightarrow \mathrm{Val}$, which have been reported in PBP2 of strain CDC-6, but for which no sequence accession number was provided, are omitted from this figure.

S. aureus strains that do not exhibit a BORSA phenotype, amino acid substitutions in the transpeptidase domain of PBP2 are unusual, and do not promote resistance.

We then sequenced $p b p 2$ from the ST1 BORSA strain MA15 and the ST25 BORSA strain MSH12 for comparative purposes. Surprisingly, PBP2 from the ST1 BORSA strain MA15 harboured a single Asp $_{606} \rightarrow$ Val substitution in its transpeptidase domain, at the same site as $\mathrm{Asp}_{606} \rightarrow \mathrm{Ala}$ in the oxacillin-susceptible strain ATCC 6538P (Table 4). The ST25 BORSA strain MSH12 possessed four substitutions in its transpeptidase domain $\left(\mathrm{Ala}_{405} \rightarrow \mathrm{Val} ; \mathrm{Met}_{580} \rightarrow \mathrm{Thr}\right.$; $\mathrm{Gln}_{629} \rightarrow$ Pro; $\mathrm{Asn}_{650} \rightarrow$ Asp), all of them different from that of the ST1 strain (Table 4). As the ST1 and ST25 BORSA did not have any common substitutions, we sequenced a $p b p 2$ segment encoding amino acids 278-701 of PBP2, from seven additional ST25 BORSA and the ST47 strain MA6. Each of the ST25 isolates had the $\operatorname{Gln}_{629} \rightarrow$ Pro substitution that was present in MSH12, and previously noted in the prototypic BORSA strain CDC-6 (Hackbarth et al., 1995). This defining feature of ST25 BORSA is the only substitution in strains MA8 and MA9 (Table 4). The other ST25 strains, MSH12, MA4, MA13, MA14, MSH7 and OGH2, harboured three, one, one, four, two and one additional substitutions, respectively, that were unique to each isolate. The ST47 isolate MA6 had a single $\mathrm{Thr}_{586} \rightarrow$ Ile substitution in the transpeptidase domain.

This substitution is of interest because it is adjacent to the ${ }_{583}$ KTG penicillin-binding motif, altering the normal ${ }_{583} \mathrm{KTGT}_{586}$ sequence to ${ }_{583} \mathrm{KTGI}$, and replaces a small polar amino acid with one with a bulky hydrophobic side chain. When the PBP2 sequence of $S$. aureus is aligned with that of the PBP $2 \mathrm{x}$ protein of Strep. pneumoniae, the

Table 4. Comparison of amino acid substitutions in the transpeptidase domain of known PBP2 sequences compared to BORSA

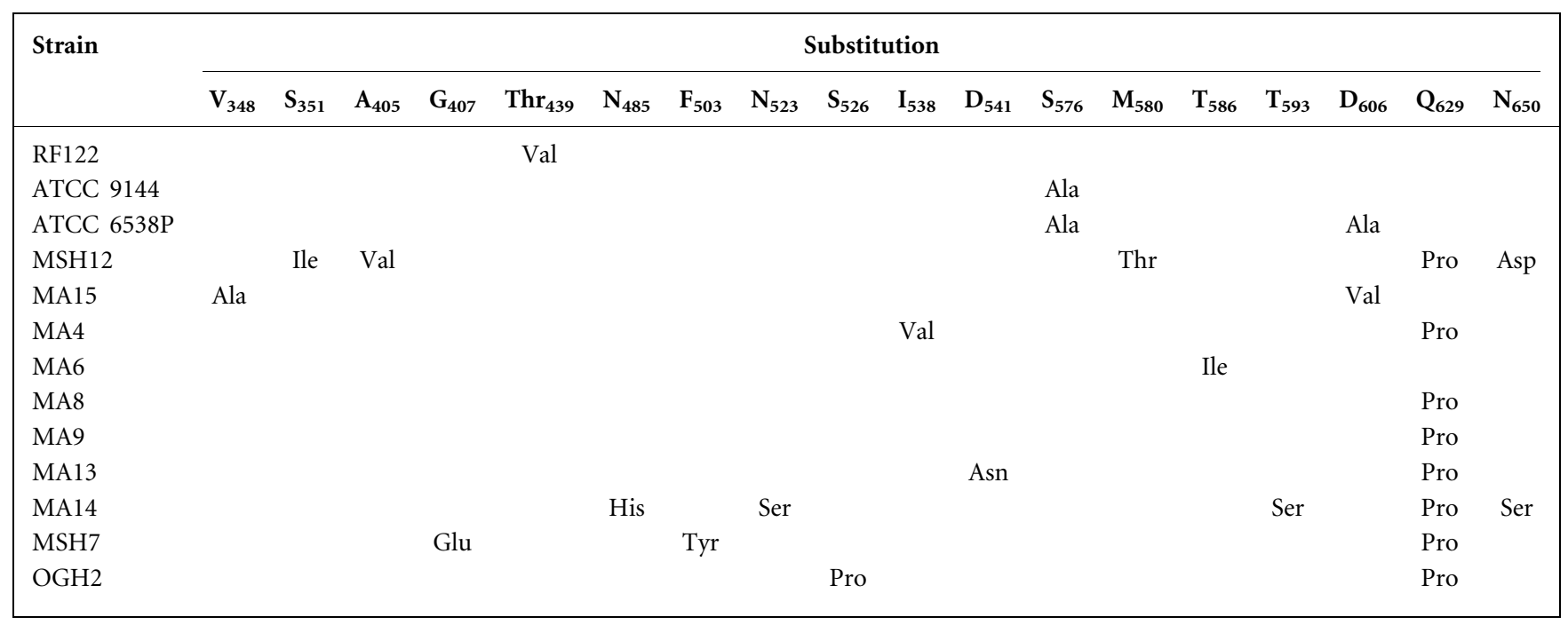


${ }_{583} \mathrm{KTGT}$ sequence in PBP2 is synonymous with the similar ${ }_{547} \mathrm{KSGT}_{550}$ penicillin-binding motif in PBP $2 \mathrm{x}$ (data not shown). Of particular interest, both laboratory-induced and clinical Strep. pneumoniae isolates that exhibit resistance to the extended-spectrum $\beta$-lactam antibiotic cefotaxime harbour a $\mathrm{Thr}_{550} \rightarrow$ Ala substitution $\left({ }_{547} \mathrm{KSGA}_{550}\right)$ adjacent to this motif (Grebe \& Hakenbeck, 1996). Curiously, this substitution promotes cefotaxime resistance, but results in loss of cross-resistance to oxacillin or benzyl penicillin (Grebe \& Hakenbeck, 1996). Similarly, it has been noted that a spontaneously selected $\mathrm{PrO}_{458} \rightarrow$ Leu substitution adjacent to the ${ }_{454} \mathrm{SFN}$ penicillin-binding motif of PBP2 from $S$. aureus promotes reduced affinity for the $\beta$-lactam ceftizoxime without affecting the binding of other $\beta$-lactam antibiotics (Leski \& Tomasz, 2005). Therefore, it is evident that a single amino acid substitution can exert a complex phenotype with respect to susceptibility or resistance towards different $\beta$-lactam antibiotics. This may explain why BORSA strains MA15 and MSH12, which lack blaZ, exhibit MIC values for oxacillin that are higher than those determined for penicillin.

\section{Expression of BORSA PBP2 confers a borderline-resistant phenotype upon $S$. aureus RN6390}

When PCR products containing the $p f r A p b p 2$ genes from the MSSA strain ATCC 25923, and BORSA strains MA15 and MSH12, were cloned into pRN5548 for expression in $S$. aureus RN6390, increased expression of an approximately $81 \mathrm{kDa}$ protein corresponding to the expected size of PBP2 was observed, but not in RN6390 harbouring pRN5548 alone (Fig. 2). Although each RN6390 derivative exhibited increased PBP2 expression, the MIC for oxacillin was not

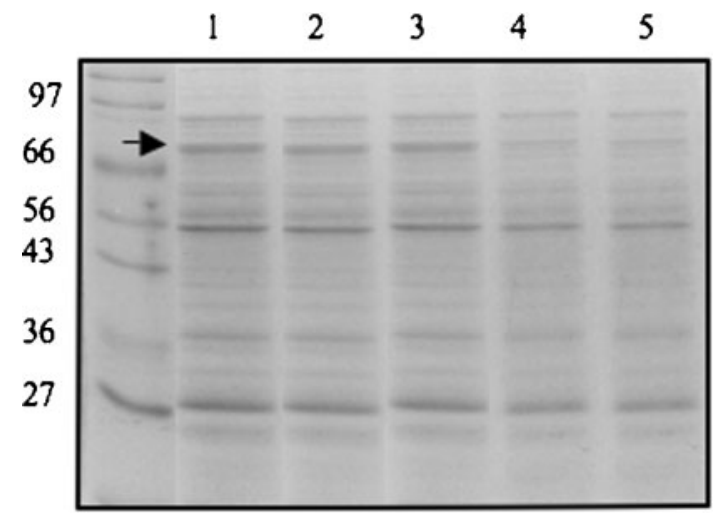

Fig. 2. SDS-PAGE of total cell lysate protein $(10 \mu \mathrm{g})$ derived from S. aureus RN6390 harbouring plasmids pRN_pbMA (lane 1), pRN_pbMS (lane 2), pRN_pbAT (lane 3), pRN5548 (lane 4) or RN6390 alone (lane 5). The black arrow points to a $\sim 82 \mathrm{kDa}$ protein corresponding to the expected size of PBP2, which is expressed at a higher level due to plasmids pRN_pbMA, pRN_pbMS and pRN_pbAT, but not with vector alone (lane 4) or in RN6390 without vector (lane 5). altered in RN6390 carrying pb_AT derived from the meticillin-sensitive strain ATCC 25923, whereas S. aureus RN6390 harbouring pRN_pbMS or pRN_pbMA plasmids had MICs that were comparable to those of the parent BORSA strains MSH12 and MA15, respectively (Table 5). The $p b p 2$ genes from strains MA15 and MSH12 were selected for expression in S. aureus RN6390 because these strains lacked blaZ-encoded $\beta$-lactamase as a potential contributor to the BORSA phenotype. From these data, we conclude that the BORSA $p b p 2$ gene alone is sufficient to confer a borderline-resistance phenotype. As the ST1 strain MA15 possessed just one amino acid substitution, Asp $_{606} \rightarrow$ Val, in the transpeptidase domain of its PBP2, and expression of this PBP2 in S. aureus RN6390 promoted an oxacillin MIC of $4 \mu \mathrm{g} \mathrm{ml}^{-1}$ (Table 5), our findings strongly implicate a causative role for this substitution in promoting a BORSA phenotype. Although the $\mathrm{Gln}_{629} \rightarrow$ Pro substitution appears to be a common feature of all ST25 BORSA isolates, we cannot exclude the possibility that this substitution is a characteristic feature of the ST25 genetic background, irrespective of BORSA phenotype. Future studies will focus on assessing the influence of this and other substitutions that we have identified as specific mediators of a BORSA phenotype.

\section{Analysis of clonal associations among BORSA}

Prior to our study, it was known that most BORSA shared a number of common properties, including a high degree of genetic relatedness, the 94/96 phage type, and a $17 \cdot 2 \mathrm{~kb}$ plasmid that encodes blaZ (Barg et al., 1991; Massidda et al., 1996; McMurray et al., 1990). Our study has established that these isolates are of the ST25 genetic lineage, but also that the BORSA phenotype is not restricted to this lineage. In this context, our data allow for the first time a comparison of the genetic backgrounds of different BORSA strains in relation to the eight major clonal complexes (CCs) that define the population structure of S. aureus (Feil et al., 2003). Strain MA15 was identified as ST1, which is the founding member of the CC1. Other ST1 strains within the CC1 complex include the high-virulence community-acquired MRSA strain MW2, and community-acquired meticillin-susceptible strain MSSA476 (Holden et al., 2004), but these strains

Table 5. Effect of expressing recombinant PBP2s on MIC values of $S$. aureus RN6390 for penicillin and oxacillin

\begin{tabular}{|lcc|}
\hline \multirow{2}{*}{ Strain (plasmid) } & \multicolumn{2}{c|}{ MIC $\left(\boldsymbol{\mu g ~ \mathbf { ~ m } ^ { - \mathbf { 1 } } )}\right.$ for: } \\
\cline { 2 - 3 } & Penicillin $^{\star}$ & Oxacillin \\
\hline RN6390 & 0.023 & $<0 \cdot 25$ \\
RN6390 (pRN_pbAT) & 0.023 & 0.25 \\
RN6390 (pRN_pbMS) & 0.032 & 4 \\
RN6390 (pRN_pbMA) & 0.064 & 4 \\
\hline
\end{tabular}

${ }^{*} \mathrm{MIC}$ values for penicillin were determined in dilution medium lacking $\mathrm{NaCl}$. 
do not have the $\mathrm{Asp}_{606} \rightarrow \mathrm{Val}$ substitution that we identified in PBP2 of strain MA15. Other ST1 isolates in the S. aureus MLST database (http://saureus.mlst.net/) include MSSA nasal-carriage isolates, endemic hospital-associated MSSA, and community-acquired MSSA and MRSA, originating from Canada, Denmark, Australia and the USA. As strains of this genetic background have a proven ability to acquire $m e c A$-mediated resistance, there is presumably no selection pressure for maintenance of the $\mathrm{Asp}_{606} \rightarrow$ Val substitution in the ST1 background.

Similarly, the ST47 group, to which BORSA strain MA6 was assigned, is a single-locus variant of ST45, which defines CC45 (Feil et al., 2003), and includes the Berlin strain of epidemic MRSA (Robinson \& Enright, 2004). The nine ST47 isolates in the $S$. aureus MLST database are exclusively meticillin susceptible, but are annotated as the progenitor of the ST45 Berlin strain of epidemic MRSA. Therefore, this genetic background can also readily acquire mecA-mediated resistance, which would eliminate any positive selection for maintenance of the single $\mathrm{Thr}_{586} \rightarrow$ Ile substitution that we have noted in the transpeptidase domain of this strain.

The ST25 clone to which the majority of BORSA belong is the founding member of CC25. There are presently 34 ST25 isolates in the MLST database; these are exclusively meticillin susceptible, and do not appear to have spawned any successful variants, because reducing the stringency of comparison to find one-, two-, three-, or four-locus variants identifies 17 additional isolates represented by 14 STs. As these STs are not in any of the five major CCs to which MRSA belong (Enright et al., 2002), it appears that members of CC25 cannot readily acquire mecA-mediated resistance. For this reason, we propose that there is a positive selection for stable maintenance of the diverse amino acid substitutions that we have noted in nosocomial isolates belonging to the ST25 genetic background. Intriguingly, a recent study that employed MLST to assess genetic variation among 258 bovine-associated S. aureus isolates from the USA, Chile and the UK (Smith et al., 2005) revealed that ST25 was one of two predominant STs, ST25 $(n=73)$ and ST124 $(n=86)$, which collectively formed $>60 \%$ of bovine isolates. The ST25 strain was the most widely disseminated, being found in the UK, and in 27 of 43 herds that were tested in the USA, and was also significantly more likely to be isolated from teat skin than milk.

Potentially, the prevalence of ST25 S. aureus as a bovinecolonizing strain could be related to their propensity to acquire amino acid substitutions in PBP2, and the management of dairy herds (Chriel \& Dietz, 2003), in which antibiotics can be administered during 'dry' or nonlactating periods, as a prophylaxis to prevent the incidence of mastitis during future lactation (Bradley \& Green, 2004). Such practices could select for ST25 BORSA as a predominant colonizing strain of dairy cattle, and provide a stable reservoir for maintenance of the BORSA phenotype and transmission to humans.
An interesting feature of the ST25 BORSA for which PBP2 sequences were determined is the remarkable variation, apart from $\mathrm{Gln}_{629} \rightarrow$ Pro, in the other amino acid substitutions that are present. Studies of $S$. aureus population structure, combined with genome-sequencing projects, strongly support the close association of specific substitutions with strains of a common genetic background. The ST1 strains MW2 and MSSA476 were isolated on different continents (Holden et al., 2004; Lindsay \& Holden, 2004), and harbour a common $\mathrm{Pro}_{285} \rightarrow$ Ala substitution, while the closely related MRSA strains N315 and Mu50 isolated in Japan in 1982 and 1997, respectively (Enright et al., 2002; Kuroda et al., 2001), share a single $\mathrm{Tyr}_{197} \rightarrow$ Cys substitution (Table 2). It is therefore remarkable that most of the ST25 BORSA exhibit unique strain-specific substitutions in their transpeptidase domains (Table 4). The occurrence of eight substitutions in the partial PBP2 sequence of strain MA14 may indicate a high rate of point mutation within the ST25 group. Alternatively, or in addition, these may be compensatory mutations that arise in response to antibiotic exposure.

\section{ACKNOWLEDGEMENTS}

J.N. and M.L. were the recipients of scholarship awards from the National Sciences and Engineering Research Council of Canada.

\section{REFERENCES}

Archer, G. L. (1998). Staphylococcus aureus: a well-armed pathogen. Clin Infect Dis 26, 1179-1181.

Asahi, Y., Takeuchi, Y. \& Ubukata, K. (1999). Diversity of substitutions within or adjacent to conserved amino acid motifs of penicillin-binding protein 2X in cephalosporin-resistant Streptococcus pneumoniae isolates. Antimicrob Agents Chemother 43, 1252-1255.

Baba, T., Takeuchi, F., Kuroda, M. \& 11 other authors (2002). Genome and virulence determinants of high virulence communityacquired MRSA. Lancet 359, 1819-1827.

Balslev, U., Bremmelgaard, A., Svejgaard, E., Havstreym, J. \& Westh, H. (2005). An outbreak of borderline oxacillin-resistant Staphylococcus aureus (BORSA) in a dermatological unit. Microb Drug Resist 11, 78-81.

Barg, N., Chambers, H. \& Kernodle, D. (1991). Borderline susceptibility to antistaphylococcal penicillins is not conferred exclusively by the hyperproduction of beta-lactamase. Antimicrob Agents Chemother 35, 1975-1979.

Boyle-Vavra, S., Yin, S., Challapalli, M. \& Daum, R. S. (2003). Transcriptional induction of the penicillin-binding protein 2 gene in Staphylococcus aureus by cell wall-active antibiotics oxacillin and vancomycin. Antimicrob Agents Chemother 47, 1028-1036.

Bradley, A. J. \& Green, M. J. (2004). The importance of the nonlactating period in the epidemiology of intramammary infection and strategies for prevention. Vet Clin North Am Food Anim Pract 20, 547-568.

Chriel, M. \& Dietz, H. H. (2003). Medication of production animals cure of malfunctioning animals or production systems? Acta Vet Scand 98, 65-70.

Dessen, A., Mouz, N., Gordon, E., Hopkins, J. \& Dideberg, O. (2001). Crystal structure of PBP2x from a highly penicillin-resistant 
Streptococcus pneumoniae clinical isolate: a mosaic framework containing 83 mutations. J Biol Chem 276, 45106-45112.

Diep, B. A., Gill, S. R., Chang, R. F. \& 9 other authors (2006). Complete genome sequence of USA 300, an epidemic clone of community-acquired meticillin-resistant Staphylococcus aureus. Lancet 367, 731-739.

Enright, M. C., Day, N. P., Davies, C. E., Peacock, S. J. \& Spratt, B. G. (2000). Multilocus sequence typing for characterization of methicillin-resistant and methicillin-susceptible clones of Staphylococcus aureus. J Clin Microbiol 38, 1008-1015.

Enright, M. C., Robinson, D. A., Randle, G., Feil, E. J., Grundmann, H. \& Spratt, B. G. (2002). The evolutionary history of methicillinresistant Staphylococcus aureus (MRSA). Proc Natl Acad Sci U S A 99, 7687-7692.

Feil, E. J. \& Enright, M. C. (2004). Analyses of clonality and the evolution of bacterial pathogens. Curr Opin Microbiol 7, 308-313.

Feil, E. J., Cooper, J. E., Grundmann, H. \& 9 other authors (2003). How clonal is Staphylococcus aureus? J Bacteriol 185, 3307-3316.

Feil, E. J., Li, B. C., Aanensen, D. M., Hanage, W. P. \& Spratt, B. G. (2004). eBURST: inferring patterns of evolutionary descent among clusters of related bacterial genotypes from multilocus sequence typing data. J Bacteriol 186, 1518-1530.

Fitzgerald, J. R., Hartigan, P. J., Meaney, W. J. \& Smyth, C. J. (2000). Molecular population and virulence factor analysis of Staphylococcus aureus from bovine intramammary infection. J Appl Microbiol 88, 1028-1037.

Frere, J. M. \& Joris, B. (1985). Penicillin-sensitive enzymes in peptidoglycan biosynthesis. Crit Rev Microbiol 11, 299-396.

Fuller, E., Elmer, C., Nattress, F., Ellis, R., Horne, G., Cook, P. \& Fawcett, T. (2005). Beta-lactam resistance in Staphylococcus aureus cells that do not require a cell wall for integrity. Antimicrob Agents Chemother 49, 5075-5080.

Ghuysen, J. M. (1991). Serine beta-lactamases and penicillin-binding proteins. Annu Rev Microbiol 45, 37-67.

Ghuysen, J. M. (1994). Molecular structures of penicillin-binding proteins and beta-lactamases. Trends Microbiol 2, 372-380.

Gillaspy, A. F., Worrell, V., Orvis, J., Roe, B. A., Dyer, D. W. \& landolo, J. J. (2006). The Staphylococcus aureus NCTC8325 genome. In Gram Positive Pathogens, 2nd edn. Edited by V. Fischetti, R. P. Novick, J. Ferretti, D. Portnoy \& J. Rood. Washington, DC: American Society for Microbiology.

Grebe, T. \& Hakenbeck, R. (1996). Penicillin-binding proteins $2 \mathrm{~b}$ and $2 \mathrm{x}$ of Streptococcus pneumoniae are primary resistance determinants for different classes of beta-lactam antibiotics. Antimicrob Agents Chemother 40, 829-834.

Hackbarth, C. J., Kocagoz, T., Kocagoz, S. \& Chambers, H. F. (1995). Point mutations in Staphylococcus aureus PBP 2 gene affect penicillin-binding kinetics and are associated with resistance. Antimicrob Agents Chemother 39, 103-106.

Hartman, B. J. \& Tomasz, A. (1984). Low-affinity penicillin-binding protein associated with beta-lactam resistance in Staphylococcus aureus. J Bacteriol 158, 513-516.

Hiramatsu, K., Cui, L., Kuroda, M. \& Ito, T. (2001). The emergence and evolution of methicillin-resistant Staphylococcus aureus. Trends Microbiol 9, 486-493.

Holden, M. T., Feil, E. J., Lindsay, J. A. \& 42 other authors (2004). Complete genomes of two clinical Staphylococcus aureus strains: evidence for the rapid evolution of virulence and drug resistance. Proc Natl Acad Sci U S A 101, 9786-9791.

Ito, T., Katayama, Y., Asada, K., Mori, N., Tsutsumimoto, K., Tiensasitorn, C. \& Hiramatsu, K. (2001). Structural comparison of three types of staphylococcal cassette chromosome mec integrated in the chromosome in methicillin-resistant Staphylococcus aureus. Antimicrob Agents Chemother 45, 1323-1336.

Kernodle, D. S., Classen, D. C., Stratton, C. W. \& Kaiser, A. B. (1998). Association of borderline oxacillin-susceptible strains of Staphylococcus aureus with surgical wound infections. J Clin Microbiol 36, 219-222.

Keseru, J. S., Gal, Z., Barabas, G., Benko, I. \& Szabo, I. (2005). Investigation of beta-lactamases in clinical isolates of Staphylococcus aureus for further explanation of borderline methicillin-resistance. Chemotherapy 51, 300-304.

Kuroda, M., Ohta, T., Uchiyama, I. \& 34 other authors (2001). Whole genome sequencing of meticillin-resistant Staphylococcus aureus. Lancet 357, 1225-1240.

Laible, G., Spratt, B. G. \& Hakenbeck, R. (1991). Interspecies recombinational events during the evolution of altered PBP 2x genes in penicillin-resistant clinical isolates of Streptococcus pneumoniae. Mol Microbiol 5, 1993-2002.

Leski, T. A. \& Tomasz, A. (2005). Role of penicillin-binding protein 2 (PBP2) in the antibiotic susceptibility and cell wall cross-linking of Staphylococcus aureus: evidence for the cooperative functioning of PBP2, PBP4, and PBP2A. J Bacteriol 187, 1815-1824.

Lindsay, J. A. \& Holden, M. T. (2004). Staphylococcus aureus: superbug, super genome? Trends Microbiol 12, 378-385.

Louie, L., Matsumura, S. O., Choi, E., Louie, M. \& Simor, A. E. (2000). Evaluation of three rapid methods for detection of methicillin resistance in Staphylococcus aureus. J Clin Microbiol 38, 2170-2173.

Louie, L., Goodfellow, J., Mathieu, P., Glatt, A., Louie, M. \& Simor, A. E. (2002). Rapid detection of methicillin-resistant staphylococci from blood culture bottles by using a multiplex PCR assay. J Clin Microbiol 40, 2786-2790.

Massanari, R. M., Pfaller, M. A., Wakefield, D. S., Hammons, G. T. McNutt, L. A., Woolson, R. F. \& Helms, C. M. (1988). Implications of acquired oxacillin resistance in the management and control of Staphylococcus aureus infections. J Infect Dis 158, 702-709.

Massidda, O., Montanari, M. P. \& Varaldo, P. E. (1992). Evidence for a methicillin-hydrolysing beta-lactamase in Staphylococcus aureus strains with borderline susceptibility to this drug. FEMS Microbiol Lett 71, 223-227.

Massidda, O., Montanari, M. P., Mingoia, M. \& Varaldo, P. E. (1996). Borderline methicillin-susceptible Staphylococcus aureus strains have more in common than reduced susceptibility to penicillinaseresistant penicillins. Antimicrob Agents Chemother 40, 2769-2774.

McDougal, L. K. \& Thornsberry, C. (1986). The role of betalactamase in staphylococcal resistance to penicillinase-resistant penicillins and cephalosporins. J Clin Microbiol 23, 832-839.

McMurray, L. W., Kernodle, D. S. \& Barg, N. L. (1990). Characterization of a widespread strain of methicillin-susceptible Staphylococcus aureus associated with nosocomial infections. I Infect Dis 162, 759-762.

Mouz, N., Di Guilmi, A. M., Gordon, E., Hakenbeck, R., Dideberg, O. \& Vernet, T. (1999). Mutations in the active site of penicillin-binding protein PBP2x from Streptococcus pneumoniae. Role in the specificity for beta-lactam antibiotics. J Biol Chem 274, 19175-19180.

Murakami, K., Fujimura, T. \& Doi, M. (1994). Nucleotide sequence of the structural gene for the penicillin-binding protein 2 of Staphylococcus aureus and the presence of a homologous gene in other staphylococci. FEMS Microbiol Lett 117, 131-136.

National Committee for Clinical Laboratory Standards (2003). Methods for Dilution Antimicrobial Susceptibility Tests for Bacteria that Grow Aerobically: Approved Standard, 6th edn. NCCLS 
document M7-A6. Wayne PA: National Committee for Clinical Laboratory Standards.

Novick, R. P., Ross, H. F., Projan, S. J., Kornblum, J., Kreiswirth, B. \& Moghazeh, S. (1993). Synthesis of staphylococcal virulence factors is controlled by a regulatory RNA molecule. EMBO J 12, 3967-3975.

Pinho, M. G., de Lencastre, H. \& Tomasz, A. (1998). Transcriptional analysis of the Staphylococcus aureus penicillin-binding protein 2 gene. J Bacteriol 180, 6077-6081.

Pinho, M. G., de Lencastre, H. \& Tomasz, A. (2001a). An acquired and a native penicillin-binding protein cooperate in building the cell wall of drug-resistant staphylococci. Proc Natl Acad Sci U S A 98, 10886-10891.

Pinho, M. G., Filipe, S. R., de Lencastre, H. \& Tomasz, A. (2001b). Complementation of the essential peptidoglycan transpeptidase function of penicillin-binding protein 2 (PBP2) by the drug resistance protein PBP2A in Staphylococcus aureus. J Bacteriol 183, 6525-6531.

Rice, K., Huesca, M., Vaz, D. \& McGavin, M. J. (2001). Variance in fibronectin binding and $f n b$ locus polymorphisms in Staphylococcus aureus: identification of antigenic variation in a fibronectin binding protein adhesin of the epidemic CMRSA-1 strain of methicillinresistant S. aureus. Infect Immun 69, 3791-3799.

Robinson, D. A. \& Enright, M. C. (2004). Multilocus sequence typing and the evolution of methicillin-resistant Staphylococcus aureus. Clin Microbiol Infect 10, 92-97.

Simor, A. E., Ofner-Agostini, M., Bryce, E., Green, K., McGeer, A., Mulvey, M. \& Paton, S. (2001). The evolution of methicillin-resistant Staphylococcus aureus in Canadian hospitals: 5 years of national surveillance. CMAJ 165, 21-26.

Simor, A. E., Ofner-Agostini, M., Bryce, E., McGeer, A., Paton, S. \& Mulvey, M. R. (2002). Laboratory characterization of methicillinresistant Staphylococcus aureus in Canadian hospitals: results of
5 years of National Surveillance, 1995-1999. J Infect Dis 186, 652-660.

Smith, E. M., Green, L. E., Medley, G. F. \& 7 other authors (2005). Multilocus sequence typing of intercontinental bovine Staphylococcus aureus isolates. J Clin Microbiol 43, 4737-4743.

Suggs, A. H., Maranan, M. C., Boyle-Vavra, S. \& Daum, R. S. (1999). Methicillin-resistant and borderline methicillin-resistant asymptomatic Staphylococcus aureus colonization in children without identifiable risk factors. Pediatr Infect Dis J 18, 410-414.

Tortosa, P. \& Dubnau, D. (1999). Competence for transformation: a matter of taste. Curr Opin Microbiol 2, 588-592.

van Griethuysen, A., Bes, M., Etienne, J., Zbinden, R. \& Kluytmans, J. (2001). International multicenter evaluation of latex agglutination tests for identification of Staphylococcus aureus. J Clin Microbiol 39, 86-89.

Varaldo, P. E. (1993). The 'borderline methicillin-susceptible' Staphylococcus aureus. J Antimicrob Chemother 31, 1-4.

Varaldo, P. E., Montanari, M. P., Biavasco, F., Manso, E., Ripa, S. \& Santacroce, F. (1993). Survey of clinical isolates of Staphylococcus aureus for borderline susceptibility to antistaphylococcal penicillins. Eur J Clin Microbiol Infect Dis 12, 677-682.

Yamazumi, T., Marshall, S. A., Wilke, W. W., Diekema, D. J., Pfaller, M. A. \& Jones, R. N. (2001). Comparison of the Vitek Gram-Positive Susceptibility 106 card and the MRSA-screen latex agglutination test for determining oxacillin resistance in clinical bloodstream isolates of Staphylococcus aureus. J Clin Microbiol 39, 53-56.

Yoshida, R., Kuwahara-Arai, K., Baba, T., Cui, L., Richardson, J. F. \& Hiramatsu, K. (2003). Physiological and molecular analysis of a mecA-negative Staphylococcus aureus clinical strain that expresses heterogeneous methicillin resistance. J Antimicrob Chemother 51, 247-255. 